\title{
Role of Information on Women Consumer Decision Making on Food Quality: An Analysis Based on Visual Presentation of Dairy Quality Attributes
}

\author{
N. T. Thilakarathne, U. K. Jayasinghe-Mudalige, J. M. M. Udugama, \\ J. C. Edirisinghe and H. M. L. K. Herath \\ Received : $16^{\text {th }}$ October, 2014 / Accepted : 23rd January, 2015
}

\begin{abstract}
The purpose of this study was to examine empirically, using food safety and quality attributes presented in the Caswell's Classification as the analytical framework, whether a consumer's decision to purchase a food product at a given point of time, in this case Yoghurt and Full Cream Milk Powder, is predominately governed by a 'single' common attribute/s such as 'appearance' or by a number of other attributes (i.e. 'multiple') such as 'packaging', 'labeling', 'quality certification', and 'brand', collectively. This were examined empirically under three distinct food safety information scenarios available to consumers as the product was presented to them "visually"; (1) 'No'; (2) 'Partial'; or (3) 'Full' information about the product quality. Primary data collected from 200 women consumers from urban household settings in the Gampaha district during May to June 2014 were, in turn, used to derive a Food Quality Information Index (values ranged from 0 to 1) for five different panels derived to elaborate these information scenarios. The outcome of analysis suggests that consumer preference for these products increases as more information is available on multiple attributes, including the 'brand', 'labeling', and 'certification', or in other words, transforming those 'Credence' characteristics towards 'Experience' and/or 'Search' characteristics. Results from Chi-square analysis highlight that consumer behavior is not significantly affected by their age, civil status, education, and level of income.
\end{abstract}

Keywords: Consumer preferences, Information, Food safety and quality, Dairy processing industry

\section{INTRODUCTION}

Potential relationship between information and product quality has been studied from both theoretical and empirical point of view over several decades, and the economic rationale on this is best presented as early as in 1970s. Akerlof (1970) states that markets fail in the presence of asymmetric information, and as a result, 'bad quality' ultimately drives out 'good quality' from the market. Further, if quality cannot be 'signaled', good quality products cannot get a 'price premium' and, accordingly, only bad quality products will be offered for sale.

Most approaches towards determining product quality assume that it is "multidimensional", i.e. quality is perceived as a combination of several quality dimensions or characteristics of a product (Caswell, 2007). In the absence of a definitive list of attributes of quality, a consumer has to use and/or depend on "past experiences" and/or "visual cues" to form expectations about the product quality. In the case of food quality this is much prominent and essential as consumer concerns about the quality of certain food products, for example meat, fish and dairy, are reasonably high, and has, thus, become one of the major and increasing preoccupations of the food supply system in almost every country in the recent past (Henson and Caswell, 1999).

Economic theory suggests that in a 'perfectly competitive market' consumers make consumption decisions with 'full information' 
about product attributes and, as a result, choose the foods that maximize their utility. In the real world, however, numerous food safety information problems exist, which complicate consumers' decision-making. Nelson (1970) and Darby and Karni (1973) distinguished product quality attributes into three categories as Search, Experience and Credence. "Search" attributes such as product colors can be often determined by consumers at the point of purchase; "Experience" attributes such as tastes, can be judged after a product is purchased and used by consumers; and "Credence" attributes such as the nutritional level and safety cannot be observed by consumers either at purchase or after purchase.

The phenomenon of imperfect and asymmetric information can lead to many other problems in food markets. According to Weiss (1995), since consumers are unable to reliably identify differences in quality levels of food products, they are not willing to pay for better food safety. Consequently, firms are not in position to receive sufficient compensation to cover the higher costs due to changes in production practices aimed at improving food quality. Consequently, the lack of information prevents economic incentives from springing up to ensure production of foodstuffs of higher quality and safety. The marketing, psychology and consumer behavior literature also suggests that consumers' choice decisions are often influenced unconsciously by product factors such as brand logo and product package design. Koo (1999), for example, indicates that consumers evaluate a complex set of attributes before making their buying decision. In light of this, there are several conceptual frameworks and theoretical models developed by food economists to ascertain the level of information and quality attributes available to consumers about a food product, in general (see, for example Antle, 1995; Caswell and Modjuszka, 1996; Segerson, 1999).
Firms may also be reluctant to link food safety issues and their products in the minds of consumers. In fact, food economics theory suggests that firms that make or distribute products will invest fewer resources in reducing disease-causing contamination if they expect not to pay for injuries due to contaminated products (Antle, 1995). Caswell and Modjuszka (1996) claim that, even if firms were to attempt provide food safety information through product labels, there may be some concern from a consumer protection standpoint about firms' making unsubstantial health-risk claims in labelling or advertising. On the other hand, if firms expect to bear the costs of injuries, it is likely that they will invest more resources in reducing contamination. In fact, in the presence of food safety risks, firms may realize that the direct (e.g. liability law suits) and indirect (e.g. loss of reputation) costs are significantly greater than the costs of mitigation (i.e. costs of implementing food safety controls).

In nutshell, all these have led to the fact that an ever growing number of consumers in the current world context require more valid, relevant and timely information on the quality of products they consume.

In one prominent classification on food quality attributes, Caswell (2007) categorized food quality into several subsets of attributes such as: Food safety, Nutrition, Value, Package and Process. Based on this classification, Table 01 presents a number of 'intrinsic' and 'extrinsic' food quality attributes with special reference to common dairy products available in the marketplace, where the attributes of the physical product is referred to as intrinsic (e.g., nutritional content) while those are related to the product are named as extrinsic (e.g., brand). 
Table 01: Food quality attributes based on Caswell's classification

\begin{tabular}{|c|c|}
\hline Quality Attributes & Forms of the Attribute (for the Case of Milk Powder) \\
\hline \multirow{2}{*}{ Food Safety } & 1. Pathogens (Bacteria, Virus, Botulism, E-coli) \\
\hline & 2. Food Additives and Preservatives (Added to food, Not added to food) \\
\hline \multirow{2}{*}{ Nutrition } & 3. Fat and Cholesterol (Full cream, Non-fat, Malted) \\
\hline & 4. Calories (Low, Medium, High) \\
\hline \multirow{3}{*}{ Sensory / Organoleptic } & 5. Taste (Malted, Vanilla, Chocolate, Strawberry) \\
\hline & 6. Appearance (Soft dry powder, Liquid, Cream, Small granules) \\
\hline & 7. Smell (Vanilla, Chocolate, Without, Other) \\
\hline \multirow{4}{*}{ Value / Functional } & 8. Size $(75 \mathrm{~g}, 250 \mathrm{~g}, 400 \mathrm{~g}, 500 \mathrm{~g}, 1 \mathrm{~kg})$ \\
\hline & 9. Compositional Integrity(Yes, No) \\
\hline & 10. Package Material (Aluminum foil, Aluminum foil \& cardboard, Tetra-packed) \\
\hline & 11. Keepability (after opening) (1 Week, 1-3 Week, 3-5 Week, >5 Week) \\
\hline Process & 12. Place of Origin (Australia, New Zealand, India, Denmark, Sri Lanka) \\
\hline \multirow{2}{*}{ Text / Measurement } & 13. Certification(SLS, ISO 9001, HACCP, GMP) \\
\hline & 14. Labeling (Yes, No) \\
\hline \multirow{4}{*}{ Cues } & 15. Price (Rs. 50-100, Rs. 150-200, Rs. 250-300, >Rs. 300) \\
\hline & 16. Brand Name (Anchor, Nespray, Lakspray, Highland, Ratthi, Kothmale) \\
\hline & 17. Advertising (Television, Newspaper, Radio) \\
\hline & 18. Past Purchase Experience (Yes, No) \\
\hline
\end{tabular}

Source: Lakni and Jayasinghe-Mudalige (2009)

This study was aimed, in light of this, to examine empirically whether a consumer in her decision to purchase a dairy product, in this case full cream milk powder (FCMP) and yoghurt, is to a larger extent governed by a 'single' attribute of food quality or by a combination of a number of ('multiple') such attributes. More specifically, it assesses which of the above food quality attributes that a consumer, in general, consider, both consciously and unconsciously, to make her preference when the product was being presented to her "visually" to satisfy different levels of food safety information ranging from 'no information' to 'full information' about the product. Selection of these two dairy products - FCMP and Yoghurt - to the analysis is justified on the ground that they are popular amongst consumers due to the presence of large number of those forms of quality attributes in various degrees, for example size and shape of packaging material, and variety of textures, flavours, and nutrition levels etc. The impact of socio-economic characteristics such as age, education, income etc. of consumers in their decision making process was also taken into account.

\section{RESEARCH METHODS}

\section{Analytical Framework}

Numerous factors can motivate consumer decision making towards purchasing of a food product. While some of these may be attributed to the 'demographics' of consumer (e.g., age, education, income etc.), others can be attributed to various 'subsets of food quality' explained above.

As shown in Table 01, Four major food quality attributes were selected for the purpose of this empirical analysis, given their importance to the dairy products, including: (I) 'Sensory' [in the form of appearance]; (II) 'Value' [in the form of packaging]; (III) 'Text' [in the firm of labeling of product together with quality certification], and (IV) 'Cues' [in the firm of brand name]. 
Further, three specific levels were defined to reflect the "degree of availability" of food quality information to a consumer as she purchases a food product, including: (1) 'No' information (NI); (2) 'Partial' information (PI); and (3) 'Full' information (FI).

\section{Setting Panels to Reflect Different Information Environments}

Based on the Food Market Surveys in Sri Lanka, top four brands of Yoghurts (Y), namely: (A) "Lucky"; (B) "Highland"; (C) "Newdale", and (D) "CIC", and FCMP (M), namely: (A) "Ratthi"; (B) "Nespray"; (C) "Anchor", and (D) "Maliban" that are commonly available for a consumer in the Sri Lankan food retail marketplace were considered for the empirical analysis.

The Yoghurt and FCMP products selected were, next, set into five distinct panels such that three panels: $\mathrm{YP}_{1}, \mathrm{YP}_{2}$ and $\mathrm{YP}_{3}$ for Yoghurt, and two panels: $\mathrm{MP}_{1}$ and $\mathrm{MP}_{2}$ for FCMP as shown the Figure 01.

In the panel $\mathrm{YP}_{1}$ (Figure 01a - Top), the four yoghurts types (A to D) were filled into four "uniform size cups" separately so that no other information but "appearance" was visually presented to the potential consumer, i.e. to satisfy 'no information' criteria (i.e. $\left.\mathrm{YP}_{1}-\mathrm{NI}\right)$.

In the panel $\mathrm{YP}_{2}$ (Figure 01a - Middle), the four yoghurt types were kept in their "original cups" to satisfy 'partial information' scenario (i.e. appearance and packaging without any other information) (i.e. $\mathrm{YP}_{2}-\mathrm{PI}$ ). Notable characteristic here is that now the consumer is able to "guess" the product in terms of her prior experience on product 'size' and 'shape', in addition to what is available from Panel $\mathrm{YP}_{1}$.

In the panel $\mathrm{YP}_{3}$ (Figure 01a-Bottom), the four brands were kept "as it is" in their originals cups, i.e. to satisfy 'full information' scenario reflecting the appearance and packaging as well as the labeling, quality certification, and brand etc. (i.e. $\left.\mathrm{YP}_{3}-\mathrm{FI}\right)$.

The same procedure was administered with the four FCMP brands; however, with only two panels. In the panel MP - NI (Figure 02a - Top), $100 \mathrm{~g}$ of the respective FCMP type (A to D) were stuffed into "uniform size cups" separately, where no other information but appearance (e.g. in the form of color and smell) was available to a potential consumer, i.e. to satisfy 'no information' criteria. In the panel $\mathrm{MP}_{2}$ (Figure 02a-Bottom), a 450g packet of milk powder of each brand was used to satisfy 'full information' scenario to the consumer.

It must be noted that these panels were set discretely (i.e. five separate panels though Figure 01 shows them collectively for easy illustration) so that a respondent, at a given point of time, have an access to them in the ascending order of: (1) Panel I (i.e. NI), and then (2) Panel II and II together (i.e. PI), and finally (3) Panel I, II and III (i.e. FI).

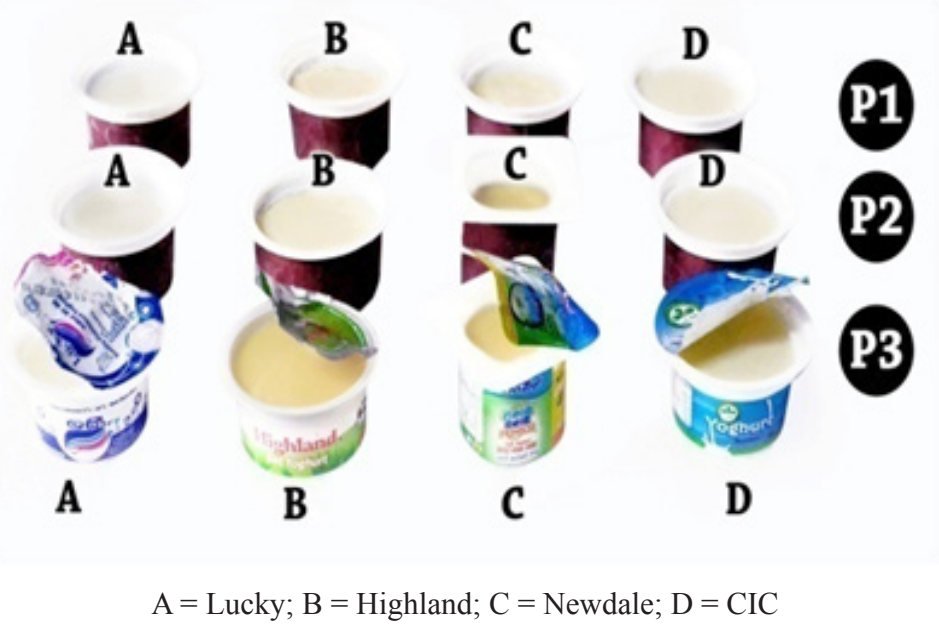

Figure 01a: Yoghurt panels 


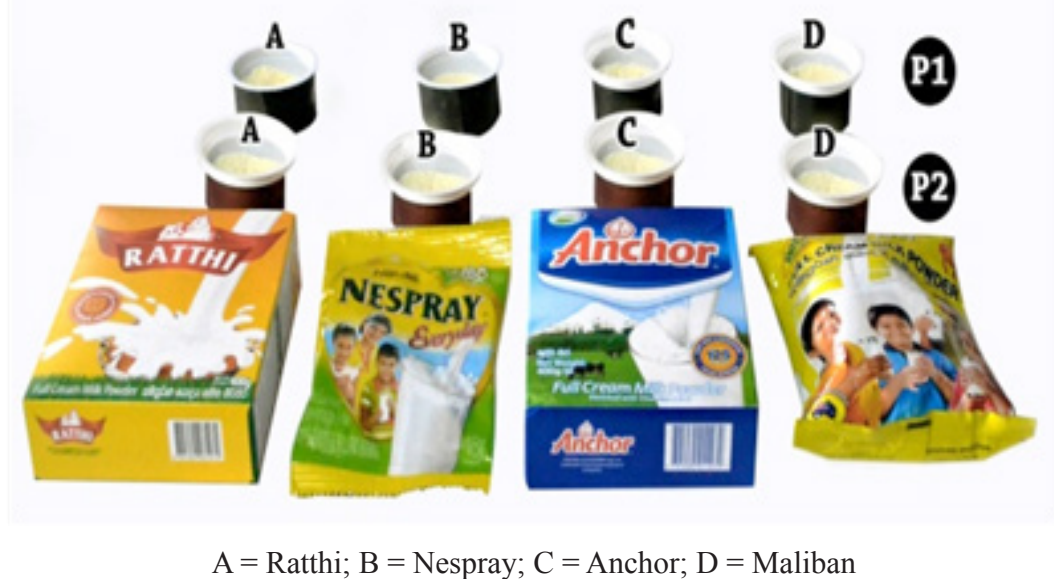

Figure 01b: FCMP Panels

\section{Development of Food Quality Information Index}

Having set the panels, at each stage, by looking at the information available to her through the panel presented visually, a respondent was needed to provide scores for a set of statements written to denote her preferences towards those attributes of concern on a four-point Likert scale (where $1=$ first choice and $4=$ fourth choice) (Table 02).

The scores given to respective statements can be used to develop an index - Food Quality Information Index (FQII), as shown on Equation 1 :

$$
\mathrm{FQII}_{\mathrm{ji}}=\left(\sum \mathrm{X}\right)_{\mathrm{ji}} / \mathrm{MPS}
$$

where, the term $X_{\mathrm{ji}}$ denotes the score given by $i^{\text {th }}$ respondent to the $j^{\text {th }}$ attribute in concern $(j=$ 'Sensory', 'Value', 'Text', 'Cues'), and MPS is the Maximum Potential Score (see, Lakni and Jayasinghe-Mudalige, 2010 for details). The FQII can be estimated for three distinct information scenarios: (I) $\mathrm{YP}_{1}-\mathrm{NI}$ and $\mathrm{MP}_{1}$ NI (appearance); (II) $\mathrm{YP}_{2}$-PI (appearance and packaging), and (III) $\mathrm{MP}_{2}-\mathrm{FI}$ and $\mathrm{YP}_{3}-$ FI (appearance, packaging, labeling, quality certification and brand).

\section{Data Collection and Analysis}

Urban women consumers involved with purchasing of value-added dairy milk products in a supermarket setting is considered as the case for empirical analysis, given their prominence in day-to-day decision on essential consumable items for the household and purchase them at the food markets (Herath et al, 2012). In consequently, it is required to select those women who used to shop by self and purchase these products frequently; thus, place a high value on information environment on food quality attributes as she makes economic decisions into the sample. On this pre-understanding, a personal interview was carried out with a cross section of women $(n=200)$ who reside in an urban household setting in the Wattala and Kelaniya Pradeshiya Sabha (Gampaha district, Western Province) with easy access to retail food markets from May to June 2014. The survey was supported by a structured questionnaire that contains those attitudinal statements and several other questions to uncover the demographics of the respondent. Each respondent was provided with maximum of three minutes to give her response to a given panel (i.e. altogether 15 minutes for five panels) and was not supposed to get support from any other person to avoid potential bias on 'time-spent' and 'learning' on effective decision making. 'Minitab' (version 15) Statistical Software was used to analyze data with appropriate tests to identify the association between demographic factors of respondents (age, civil status, education, income) under different information environments. 
Table 02: Attitudinal statements

\begin{tabular}{cl}
\hline & \multicolumn{1}{c}{ Description of Statements } \\
\hline Sensory & Appearance \\
$\mathrm{SS}_{1}$ & I am concerned about the 'external appearance' of product \\
\hline Value & Packaging \\
$\mathrm{VS}_{1}$ & I buy products with 'high quality packaging' \\
$\mathrm{VS}_{2}$ & I buy products with an 'attractive packaging material' \\
\hline $\mathrm{Text}$ & Labeling \\
$\mathrm{TS}_{1}$ & I 'believe the information' specified in the product label \\
$\mathrm{TS}_{2}$ & I am concerned about 'manufacturing and expiry date' mentioned in the label \\
$\mathrm{TS}_{3}$ & I am concerned about 'ingredients' described in the product label \\
& Certification \\
$\mathrm{TS}_{4}$ & I am concerned about the 'product certification' such as the SLS and ISO \\
\hline $\mathrm{Cues}$ & Brand Name \\
$\mathrm{CS}_{1}$ & I preferred to purchase 'specific brands' of my interest \\
\hline
\end{tabular}

\section{RESULTS AND DISCUSSION}

\section{Descriptive Statistics of Sample}

Socio-economic characteristics of respondents are summarized in Table 03. The majority of women consumers in the sample were within the age category of 31 to 45 years of Age (45.5\%), married (90\%), had a level of education up to G.C.E (A/L) (67.5\%), and earned a monthly income of greater than Rs. 30,000 (53\%). So, we may judge that outcome of analysis, at large, is more fitting with "middle-aged middle-income educated families".

The outcome of Chi-square analysis to evaluate the potential relationships between demographic characteristics of consumers (Age, Civil status, Education and Income) and the way they make decisions under different information environments (No, Partial, high) show that they were not associated significantly for both products highlighting the fact that consumers with different demographics 'value information' on equal basis in their day-to-day life as they purchase these products (Table 04). In fact, this facilitates presenting the results for the sample as a whole.

\section{Consumer Responses to Different Information Environments}

Interestingly, a significant portion of women consumers in the sample were not able to 'rank and order their preferences correctly' as they were exposed to 'No information' (P$\mathrm{NI})$ or 'Partial information' (P-PI) scenarios. For example, in the case of Yoghurt, only 59 percent respondents were able to identify and rank their true preferences under P-NI, or in other words, 41 percent of women consumers were unable to do so by looking only at Panel I, i.e. 'Sensory' (in the firm of 'appearance'). Yet, this percentage was relatively low for the case of FCMP, where nearly one third $32.5 \%$ ) of respondents were able to do so under P-NI, or in other words, almost two third of $(67.5 \%)$ of respondents were failed in this respect under 'no information' scenario (Table 05).

Consumers' ability to respond precisely was increased substantially as new information arrives. For example, in the case of four Yoghurt products considered in this study, it was increased by almost 25 percent from P-NI to P-PI as the 'Value' attribute come into play showing the form of 'packaging material' and its 'size' and 'shape' to the respondent along with the 'Sensory' attributes. In other words, with the 'partial information' in place (i.e. both Sensory and Value attributes), almost 75 percent of respondents can now correctly rank their true preferences. 
Table 03: Descriptive statistics of the sample

\begin{tabular}{lc}
\hline \multicolumn{1}{c}{ Variables } & $\%$ \\
\hline Age (Years) & \\
$18-30$ & 21.0 \\
$31-45$ & 45.5 \\
$\quad>45$ & 33.5 \\
Civil Status & \\
$\quad$ Married & 90.0 \\
$\quad$ Single & 10.0 \\
Education & \\
$\quad$ Up to G.C.E. (O/L) & 7.5 \\
$\quad$ Up to G.C.E. (A/L) & 67.5 \\
$\quad$ Tertiary & 25.0 \\
Monthly Income (Rs.) & \\
$\quad$ Less than 30,000 & 53.0 \\
30,000 $<$ MI $<50,000$ & 34.5 \\
$\quad$ More than 50,000 & 12.5 \\
Household Size & \\
$\quad$ Small ( $\leq 4)$ & 63.0 \\
Large (More than 4$)$ & 37.0 \\
\hline
\end{tabular}

Table 04: Association of consumer demographics $\&$ information environment

\begin{tabular}{lcc}
\hline Demographic & P-value & P-value \\
\cline { 2 - 3 } Characteristic & (Yoghurt) & FCMP \\
Age & 0.839 & 0.848 \\
Civil Status & 0.667 & 0.801 \\
Education & 0.792 & 0.098 \\
Income & 0.475 & 0.983 \\
\hline
\end{tabular}

Table 05: Consumer rankings on different panels

\begin{tabular}{ccccc}
\hline \multirow{2}{*}{ Panel Type } & \multicolumn{2}{c}{ Yoghurt } & \multicolumn{2}{c}{ FCMP } \\
& Rank & Did Not Rank & Rank & Did Not Rank \\
\hline \multirow{2}{*}{ P-NI } & $59 \%$ & $41 \%$ & $32.5 \%$ & $67.5 \%$ \\
& $(118)$ & $(82)$ & $(65)$ & $(135)$ \\
\multirow{2}{*}{ P-PI } & $74 \%$ & $26 \%$ & - & - \\
& $(148)$ & $(52)$ & & \\
\multirow{2}{*}{ P-FI } & $100 \%$ & $0 \%$ & $100 \%$ & $0 \%$ \\
& $(200)$ & $(0)$ & $(200)$ & $(200)$ \\
\hline
\end{tabular}

Mean Food Quality Information Index (FQII) values of the five panels used in the analysis, which was derived using the estimates of FQII from individual respondents using equation 1 are illustrated in Figure 02.

The results show that Mean Index values of all panels set for Yoghurt lie between 0.48 and 0.64 indicating that a consumer, in general, in her decision to purchase her preferred product is facilitated by enhanced information environment, i.e. availability of all or most of the quality attributes in different forms at the point of decision making (i.e. labeling, quality certification, and brand in addition to appearance and packaging) compared to visually present her with a single attribute (i.e. appearance) or few attributes like 'Sensory' and/or 'Value'. 
With regard to the forms of key attributes of food quality considered in this analysis, about 83.7 and 88.6 percent of respondents indicated that "Brand" is key to their selection of Yoghurt and FCMP, respectively, followed by "Label" (81.2\% and $74.1 \%)$ and "Certification" (78.6\% and $62.5 \%$ ) (Figure 03 ).

This implies the fact that Brand can 'act as a messenger' symbolizing the state of quality incorporated into the product, or perhaps, the firm needs to maintain for their customers (both loyal and potential).

\section{CONCLUSIONS} IMPLICATIONS

AND

POLICY

The outcome of analysis, in abstract, suggests that consumer decision making on purchasing of food products, in this case dairy products, is facilitated to a greater extent by availability of more and more information with regard to multiple attributes of food quality, especially those attributes 'visible to the decision maker', including the Sensory, Value, Text and Cues, which are offered to consumers in the food markets in the form of 'brands', 'labeling' and/or 'certification'. Further, it suggests that visualization of such information helps to transform those 'Credence' characteristics of products, including Food safety and Nutrition attributes into 'Experience' and/or 'Search' characteristics that facilitate consistent purchasing of the same product with minimum efforts as it minimizes the costs associated with searching, negotiating and verification (i.e. transaction costs).

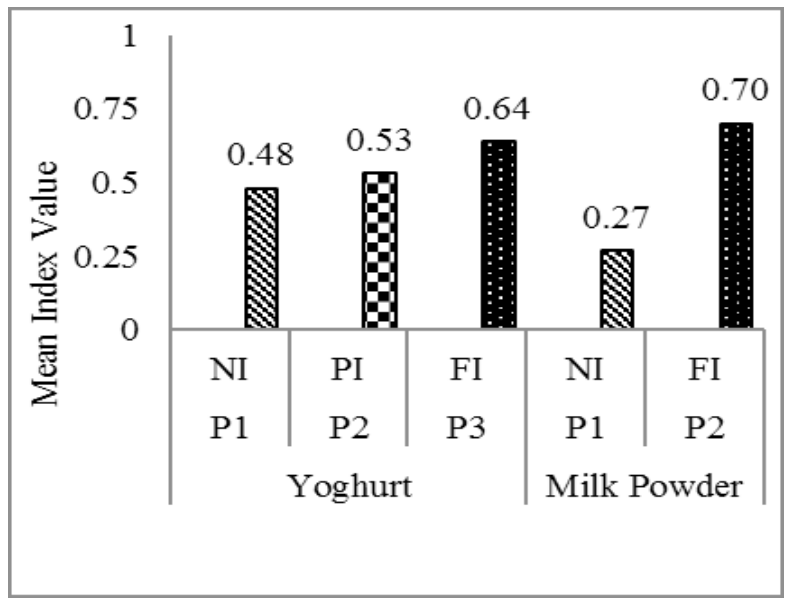

Figure 02: Mean FQII values

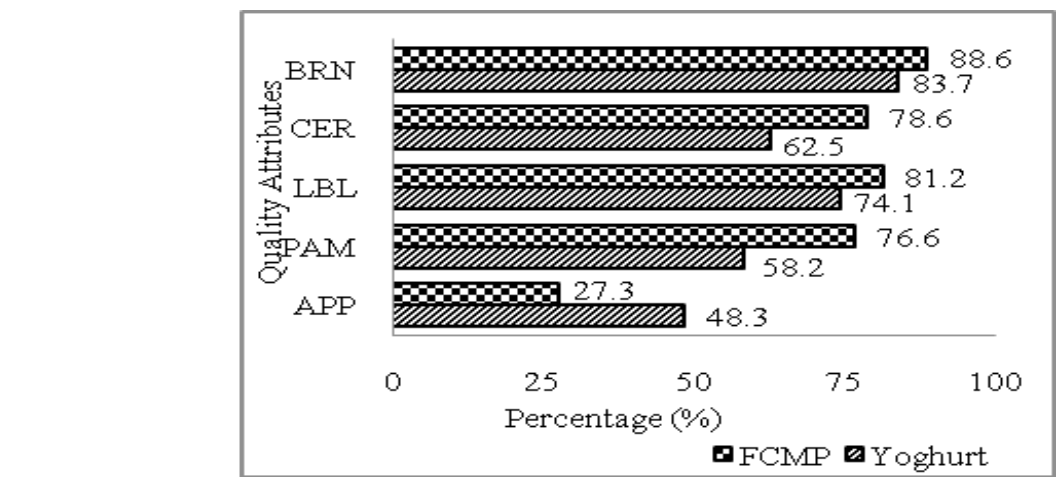

Note: $A P P=$ Appearance; $P A M=$ Package Material; $L B L=$ Labeling, $C E R=$ Certification $; B R N=$ Brand

Figure 03: Consumer preferences on different forms of food quality attributes 
The outcome of this sort of analysis benefit food producers as they can judge on what aspects of quality consumers value their products, and in turn, to respond to those quality attributes. In the context of food markets like dairy, meat and fish, which are highly sensitive to food safety and quality related hazards, this is pretty much important since transformation of 'Credence' characteristics associated with such items (e.g. food safety in terms of microbial presence, nutrition in terms of fat, cholesterol and additives) into 'Experience' and/or 'Search' (e.g. through certification such as HACCP, ISO 22000, and nutritional labeling such as "no" sugar / cholesterol / artificial food additives) through provision of accurate and timely information can increase consumer confidence to a larger extent, and for which food markets may charge a premium to cover its production and transaction costs.

This provides valuable inputs to food policy making and analysis arena, where the role of information in the food markets has often been subject to the growing criticism. At present debate exists with regard to "who should act on quality', where, from one end it is claimed that firms do not want to allocate resources sufficiently and efficiently because information provided to their clients, more particularly to the consumers, are costly to provide and is not much in use or they become 'public goods', and on the other end, it is believed that competitive food markets are in position to generate sufficient information to individuals as compared to which is produced by the government and/or any other non-profit organization, if the former is enriched with right economic incentives in the form of fiscal instruments (tax, subsidies, rebates, credits etc.) and co-regulatory mechanisms. In light of these, this study highlights that consumers 'need information' badly in their-day-to day life, thus, firms can act positively to provide such and increased their profits by charging premiums for enhanced display of quality.

\section{ACKNOWLEDGEMENTS}

The authors wish to express their gratitude to Nielsen Lanka Company (Pvt.) Ltd, for providing vital information regarding market statistics for this study and all the respondents for their valuable corporation.

\section{REFERENCES}

Akerlof, G. A. (1970). The market for 'lemons': Quality uncertainty and the market mechanism. Quarterly Journal of Economics, 84: 488-500.

Antle, J. M. (1999). The new economics of agriculture. American Journal of Agricultural Economics, 81: 993-1010.

Caswell, J. A. (2007). Study on regulatory reform and the agro-food sector. Directorate for food, agriculture and fisheries, Organization for Economic Co-operation and Development, Paris Cedex 16.

Caswell, J. A. and Modjuzska, E. M. (1996). Using informational labeling to influence the market for quality in food products. American Journal of Agricultural Economics, 78: 1248-1253.

Darby, M. R. and Karni, E. (1973). Free competition and the optimal amount of fraud. Journal of Law and Economics, 16: 67-88.

Henson, S. and Caswell, J. (1999). Food safety regulation: an overview of contemporary issues. Food Policy, 24: 589-603. 
Herath, H. M. T. K., Udugama, J. M. M. and Jayasinghe-Mudalige, U. K. (2012). Women consumer preferences for socially responsible food production attributes: evidence from urban supermarket setting in the Anuradhapura district, Journal of Agricultural Sciences, 8(2): 57 - 69.

Koo, L. C., Tao, F. K. C. and Yeung J. H. C. (1999). Preferential segmentation of restaurant attributes through conjoint analysis, International Journal of Contemporary Hospitality Management, 11(5): 242-250.

Lakni, W. A. K. I. and Jayasinghe-Mudalige, U. K. (2009). Customer-defined quality of food: An empirical investigation based on KANO Analytical methods for milk powder. Journal of Agricultural Sciences, 4: 45-58.

Nelson, P. (1970). Information and consumer behavior. Journal of Political Economics, 78, 311 329.

Segerson, K. (1999). Mandatory versus voluntary approaches to food safety. Agribusiness 15(1): 53-70.

Weiss, M D. (1995). Informational Issues for principals and agents in the market for food safety and nutrition. In: Caswell, J. A. (Ed.) Valuing Food Safety and Nutrition. p. 69-79. Colorado. 